\title{
Consumer Trust and Confidence: Some Recent Ideas in the Literature
}

\author{
Chris Fife-Schaw, Julie Barnett, Jonathan Chenoweth \\ University of Surrey \\ Guildford \\ UK \\ GU2 7XH
}

Gregory M. Morrison and Christina Lundéhn

Water Environment Technology, Chalmers University of Technology, 41296 Göteborg, Sweden

Corresponding author:

Dr Chris Fife-Schaw

Dept of Psychology

University of Surrey

Guildford, UK

GU2 7XH

e-mail: c.fife-schaw@surrey.ac.uk 


\begin{abstract}
This paper reflects on two recent debates in the consumer literature on trust that have implications for consumer relations in the water industry. The first concerns an important yet seldom made distinction between trust and confidence. The second concerns when and how trust is related to acceptance of, for example, new tariffs or new technologies, and it challenges the conventional view that trust is usually a precursor of acceptance. New conceptual models addressing these debates are described and their implications for future water-related consumer research are discussed as are potential implications for industry relationships with consumers.
\end{abstract}

\title{
Introduction
}

In this paper we present some observations about the research literature on consumer trust and satisfaction as it applies to the drinking water industry. The review draws on work that was conducted as part of the EU funded TECHNEAU project which is concerned to explore technological and regulatory options for securing safe drinking water into the future (Fife-Schaw et al, 2007). In this paper we discuss some of the recent debates about consumer trust that question some of the assumptions about the role of trust in consumer behaviour. In particular we focus on the distinction between trust and confidence and on the role of trust in fostering consumer acceptance and/or cooperation. We finish by highlighting some implications of these debates for future water consumer research and for the industry's relationships with its customers.

To structure this paper our starting point is the commonly made assertion that public trust is a key factor in encouraging cooperative action on the part of consumers (Siegrist, Earle \& Gutcher 2003). Under the European Union Water Framework Directive, water suppliers and those managing river basins will have to involve consumers in decision making and this political goal seems unlikely to succeed if consumers do not trust the key agents in this process. Similarly, where some innovation or change is proposed it is also often assumed that consumer trust is important in determining the acceptability of any proposed change. Where suppliers have to deal with water-related incidents and accidents again it is assumed that trusted suppliers and regulators will be better able to deal with these events efficiently. As we shall see however, these assumptions about the role of consumer trust in securing acceptance of the actions of the regulator and of technological developments is more problematic than it may first appear.

\section{The Concepts of Trust and Confidence}

Unfortunately many of the terms used in the study of public trust are used quite loosely and often interchangeably and this has not fostered clarity or consensus about the role of trust and confidence in consumers' relationships with suppliers and regulators. Additionally some languages do not distinguish between these concepts by the allocation of a separate word to denote them and as a consequence the literature 
contains many apparently inconsistent findings at least some of which can be attributed to terminological confusion.

Bellaby (2006) describes trust as "reliance on another agent to deliver an outcome that is in one's own interests, and, by implication, reliance on the other not to take advantage of this dependence to achieve contrary goals". Trust grows out of tacit understandings about social structure, in other words, common knowledge or taken for granted assumptions that a person or entity is 'trustworthy'. Following Siegrist et al (2003) we draw the distinction between trust, which involves some judgement of similarity of values and intentions (so called 'morality' information) and confidence which is a belief based on past experience that events will occur as expected. This may seem a subtle distinction at first but trust, in handing over agency to another, is fundamentally a feature of a social relationship where one has to impute openness, fairness and integrity (among many other possible characteristics) to another. Confidence that something will happen on the other hand does not necessarily involve trusting the motives or values of the agents involved.

While confidence and trust will often go together they do not have to. On the basis of past experience of the delivery of good quality water one might have developed confidence that there will continue to be good quality water coming out of one's tap. It may thus not be necessary or relevant to have to trust the motives and values of the supplier and to judge whether these are consistent with one's own well-being and interests. Indeed, Siegrist et al, (2003) argue in the context of electricity supplies that where past competence has led to high confidence in the supply, trust in the supplier is essentially unimportant. In the case of utilities trust only comes into play when something has gone wrong with the supply and it is no longer possible to be as confident that the supply will continue as before.

In other situations, particularly where the consumer has little past experience upon which to base estimates of competence and thus confidence, social trust will become relatively more important and may be used to impute likely competence to the relevant body. In situations where, for example, a new treatment process or regulatory framework is proposed, there will be no direct experience for consumers to use as a basis for their confidence estimates and thus social trust based on an assessment of the supplier's and regulator's motives becomes important. The so called Dual Mode models of trust and confidence suggests that both trust and confidence contribute to acceptance and willingness to cooperate. It therefore remains important to keep this distinction between confidence (based on past competence) and trust (based on value similarity) in mind when discussing this literature.

Earle and Siegrist (2006) have attempted to address the disjointed nature of the trust and confidence literature by producing a conceptual framework that explicitly acknowledges the distinctions between these and related concepts and brings them together in a single model. Their Trust, Confidence and Cooperation (TCC) framework, which is an exemplar of a Dual Mode model, is intended to be applicable to all aspects of trust between an individual and both known and unknown others including organisations. The framework is detailed in Figure 1.

The model has a number of key features. First it suggests that social trust is based on morality-relevant information, while confidence is based on performance-relevant 
information and in times of low social uncertainty, when morality information is less relevant, social trust does not play the main role in cooperation. Cooperation here implies any compliance or acceptance behaviour and could include prompt payment of water bills, acceptance of interruptions to supplies, acceptance of price increases, willingness to use less water etc. It also suggests that social trust becomes more important in times of uncertainty, when morality information becomes more relevant and it hypothesises that social trust will affect judgments of confidence both directly and via effects on perceived performance (cf. Earle and Siegrist, 2006, p388).

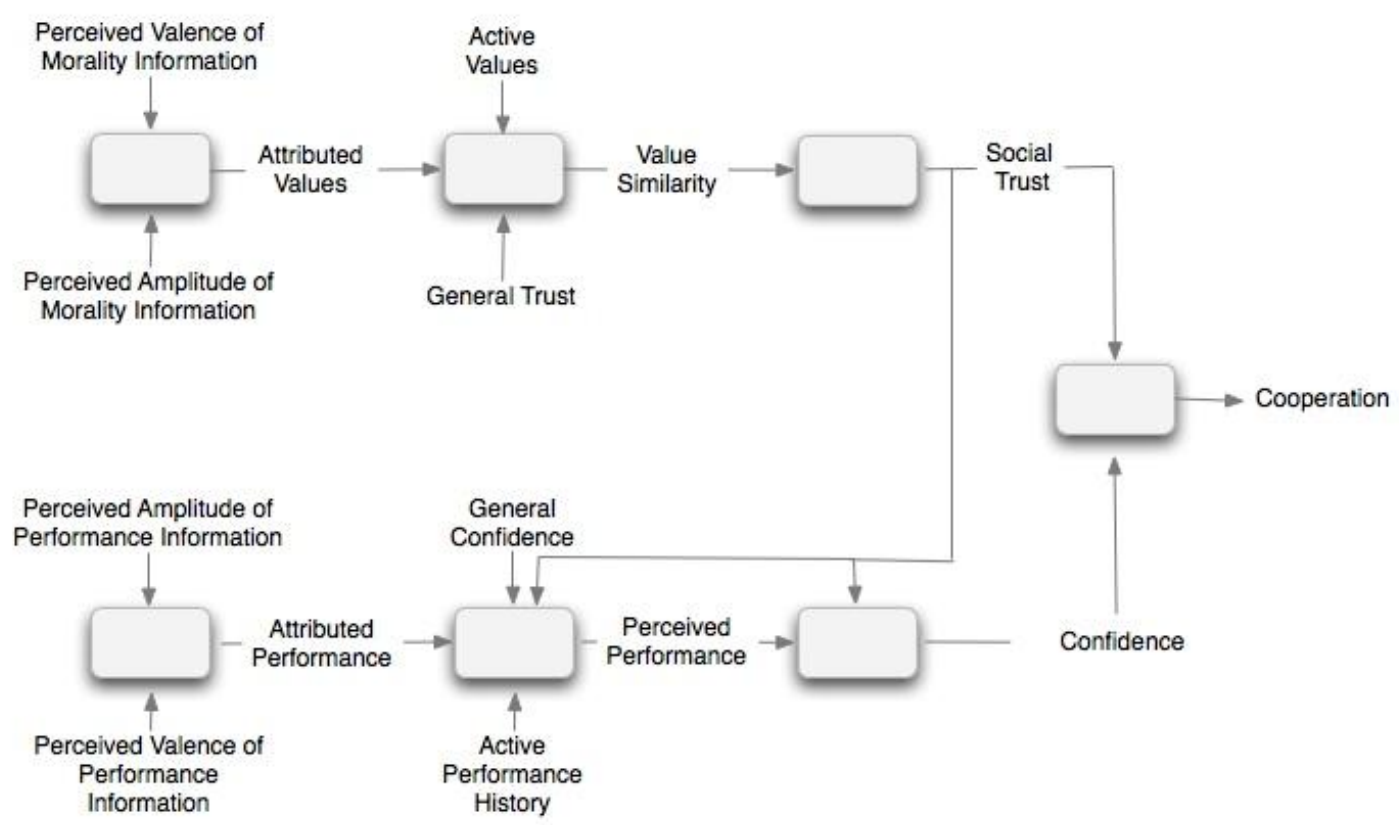

Figure 1 Earle and Siegrist's (2006) Trust, Confidence and Cooperation Framework.

Earle and Siegrist (2006) claim that social trust dominates confidence, stating that judgements of confidence presume pre-existing relations of trust. It is assumed that where social trust is present some performance failings might lower confidence a little but would not undermine a willingness to cooperate. By implication when social trust is absent or low, performance failures should lead to a swift response from consumers, such as complaints or a lack of cooperation. This is a relatively new framework supported by an as yet small number of empirical studies and these ideas are in need of testing within the water context. Before discussing the implications of this model further we discuss the role of trust in perceptions of risk, and acceptance.

Trust as a Factor in Perceptions of Risk and Acceptance

We turn now to a different part of the literature on trust which on an initial reading seems somewhat unrelated to the TCC model in that it does not make an explicit distinction between trust and confidence. A good deal of research shows that trust is related to the perception and acceptance of risk (e.g. Bord and O'Connor, 1992; 
Freudenburg, 1993; Siegrist, 1999) and it is usually assumed that trust influences perceptions of risk which in turn influence acceptability. Broadly, if an organisation or authority is trusted then perceptions of risk arising from their activities will be lower and thus the public will be more accepting of their activities. Numerous studies show correlations between trust, risk perception and acceptance but this merely demonstrates that the three constructs are linked; it does not indicate how they are linked.

Eiser, Miles \& Frewer (2002) and Poortinga and Pidgeon (2005) both address this issue and define two alternative models of the relationship between trust, risk perception and acceptance. The model suggesting that trust leads to lowered risk perception which leads to acceptance is referred to as the 'causal chain' account of trust and is illustrated in figure 2.

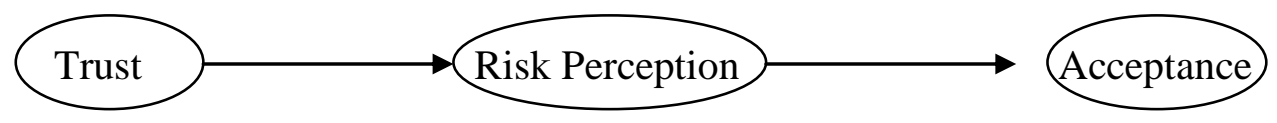

Figure 2. The Causal Chain Model

The alternative view, referred to as the 'associationist view', argues that trust is an outcome of acceptance rather than a factor implicated in its genesis. Here it is proposed that people initially respond to a potential hazard on the basis of how they feel about it. In other words, their willingness to approach or avoid the hazard is made on the basis of affective reactions which are made before extensive cognitive processing of other relevant information (cf. Finucane, Alhakami, Slovic \& Johnson, 2000). This is referred to as the 'affect heuristic' - affect precedes cognition - in certain situations emotional responses precede thought.

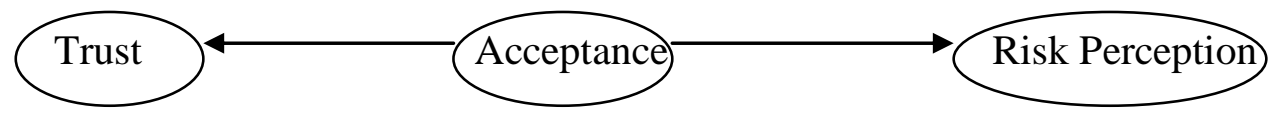

Figure 3. The Associationist Model

Both Eiser et al's (2002) and Poortinga $\quad \begin{gathered}\text { Government } \\ \text { Position }\end{gathered}$ (2005) studies suggest that in the context of food technologies the associationist model seemed to give a better account of the data. While there was, in the latter study a small residual direct influence of trust on risk perceptions it seemed that people's existing evaluations of these technologies seemed to drive levels of trust.

The implications of these studies are potentially quite far reaching. If it is true that people respond to a potential hazard using something like an affect heuristic and this response influences both trust and risk perceptions then the water industry's concern to work on improving consumer relations in order to enhance trust is unlikely to have the effect of lowering perceptions of risks from potential water supply hazards. In addition 
these models would predict that the emergence of a negative hazard event or a proposal to introduce a process like direct potable re-use which some consumers would find unpleasant might have the effect of degrading consumer trust (see also Marks, 2003). Negative events have a high signal value and trust, once lost, is quite hard to reestablish (Slovic, 1993).

While we do not suggest that fostering trust is pointless - there are plenty of other good reasons to have good relations with consumers - there may be a case for limiting expectations of positive knock-on effects in terms of acceptance of change or technological advance. What we do not yet know is the applicability of these models in various water-related contexts. For example the implication of what we have said is that the role of trust and the likelihood of acceptance will be different for proposals such as direct potable re-use proposals where the 'yuck factor' may be higher than where, for example, desalination is proposed (Haddad, 2004; Marks, 2006).

Clearly this is an area that needs further research though there is some indicative evidence already in the literature. In the 1998 Sydney Water incident, Sydney Water released advice to consumers to boil their water three times during 1998 as a result of the detection of Cryptosporidium. Despite the issue of warnings being essentially a responsible act (i.e. Sydney Water acting in the best interests of consumers) there was a decline in trust which corresponded with a lower trust in potable reuse proposals (Roseth, 2000). This was accompanied with a $19 \%$ fall in agreement that Sydney Water could be trusted to manage recycled water responsibly (presumably an assessment of a lack of competence and thus confidence rather than social trust).

\section{Integrating Recent Developments}

As we noted earlier, the above studies on the role of trust have not clearly acknowledged the trust/confidence distinction discussed in the context of the TCC. Poortinga and Pidgeon's (2005) study asked primarily about confidence via such survey items as "I feel confident that the British government adequately regulates GM food" and "I am confident that the development of GM crops is being carefully regulated". These are more assessments of competence than assessments of values or motives i.e. not social trust.

In Eiser et al's (2002) studies participants read information about food technologies ostensibly provided by a consumer organisation or the government and were invited to indicate their level of agreement with items such as "This information is trustworthy" and "I very much trust the information I have just read". In this case it is not entirely clear whether the judgements were being made about the competence of the sources to provide accurate information (confidence) or the presumed motives of these sources (social trust). Whether immediate emotional responses to reject a proposal (for example, direct potable re-use) have an impact on assessments of the motives of, as well as confidence in, a supplier or regulator remains a subject for further research and is currently being addressed in the TECHNEAU project.

The TCC model on the other hand implicitly assumes a causal chain process dominates and though it might be able to accommodate an associationist model possibly via people reflecting on past performance. The main thrust remains however that cooperation, 
which we are assuming implies aspects of acceptance, results from trust and confidence. Clearly both sets of theoretical developments need integrating into a coherent general model that indicates why and when trust and/or confidence will be important in producing cooperation and acceptance. Indeed even these concepts need further elaboration since cooperation as commonly used in the English language implies some form of positive action where as acceptance can be passive.

\section{Implications for the Water Supply Context}

As mentioned earlier there is relatively little recent research on the relationships between trust and confidence and acceptance specifically in the context of water; most of the developments and debates have occurred in different substantive domains. One notable exception is the study by Po et al(2005) in the water reuse domain. They carried out an investigation to identify the different factors that might influence their decision to accept (drink) partially recycled water. They used Ajzen's (1985) Theory of Planned Behaviour as the theoretical basis for their work to investigate communities' responses to an indirect potable scheme in Perth, Australia an area facing long-term water shortages. In response to these shortages the Managed Aquifer Recharge Scheme (MAR) method of water reuse had been proposed, which would involve the introduction of treated wastewater into the aquifer. Using a survey to elicit attitudinal responses and structural equation modelling to test tentative models of behaviour they came up with the following model:

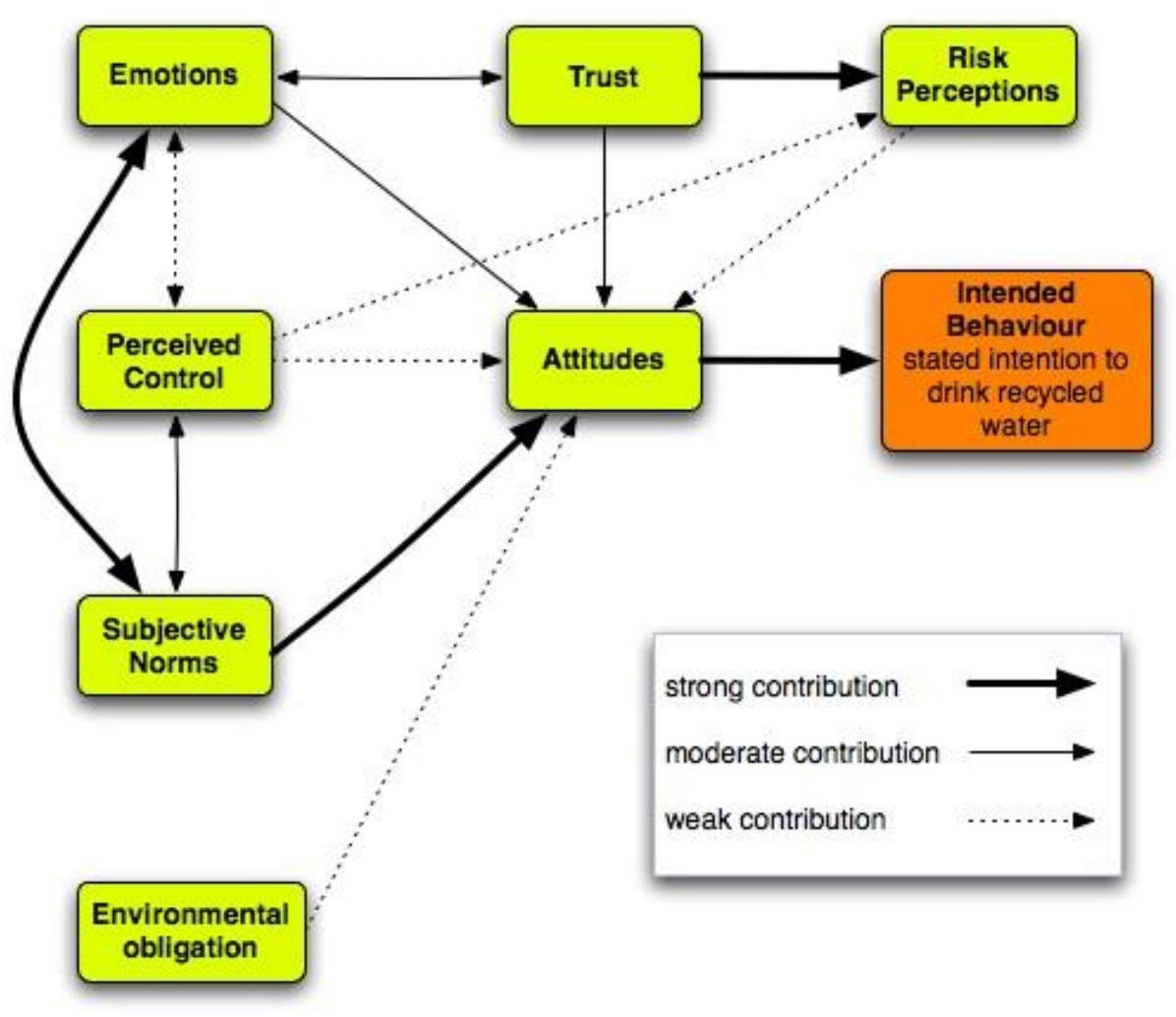




\title{
Figure 4. Model of factors that influence decisions to drink from the MAR scheme
}

\section{(simplified version)}

\author{
Source: Po et al, 2005
}

On the basis of their model, Po et al (2005) found that respondents' stated intention to drink water from the scheme could be predicted primarily by their attitudes. The key relationships in the model were between subjective norms, environmental obligation, perceived control, emotions, trust, risk perceptions and attitudes. Trust was one of the factors influencing attitudes and was also a strong predictor of risk perceptions. Where consumers had low levels of trust (actually confidence here) in the authorities to manage the scheme they perceived a greater threat from recycled water and developed more negative attitudes towards drinking the water. What is particularly relevant here is that risk perceptions, the construct(s) that educational/informational interventions would be expected to address were only weak predictors of attitudes that were the primary determinant of acceptance in this dataset.

The Po et al (2005) study was not designed to directly test either the TCC or the competing causal chain vs. associationist models; it was built around the much older and more general Theory of Planned Behaviour (TPB, Ajzen, 1985) which is not itself directly concerned with risk perceptions, emotions or trust/confidence; these constructs were added to the TPB by Po et al. However, their analysis does point to a causal role for emotions (actually measured as disgust) in determining attitudes and thence intentions and suggests at least a bi-directional relationship between emotions (disgust) and confidence. Their model is thus partially consistent with the causal chain account of acceptance but also contains elements of the associationist model.

Returning to the trust and confidence distinction the role of social trust, the idea that suppliers have consumers' interests at heart, is likely to take greater prominence in the future as proportionately more of the world's population is supplied by wholly or partially privatised supply systems. Globally $51 \mathrm{~m}$ people had water supplies involving some form of private sector involvement in 1990, with the number rising to about $460 \mathrm{~m}$ by 2002, and is expected to rise to 1.16 bn by 2015 (Owen, 2002). In the England and Wales, where the water utilities are completely privatised recent research has shown that the motives and values of private companies are indeed questioned by consumers particularly when the media focus on high profit taking and profits which leave the country yet performance in perceived to be lacking (CCWater, 2006). It remains an empirical question as to whether privatised water companies will be able to continue to foster the levels of cooperation enjoyed by existing publicly owned suppliers.

Research more directly designed to test the TCC, causal chain vs. associationist models, and an integrative model is clearly necessary. The TECHNEAU project is beginning to address this and among other things will investigate how the relationship between trust and acceptance is different for issues that vary in the strength of negative emotional reactions they elicit. A number of issues can be identified that cause, or are likely to cause emotional consumer responses. 
1. Waterborne disease outbreak, such as occurred in the Bergen Giardia case, particularly where negligence or failure to act on the part of the water company becomes evident. Even with duty-of-care one might expect an emotional response for the presence of pathogens that survive conventional treatment trains.

2. Effects of climate change on water resources and water treatment, as evidenced by rising levels of Natural Organic Matter in drinking water. As consumer awareness of issues of climate change are raised, a response might be anticipated if water supply is affected or interrupted without appropriate preparations being made.

3. High leakage rates and low replacement rate of the pipe system is becoming a challenge for many European cities with well invested systems. Considerable improvements will be required for the pipe infrastructure, which may lead to increased water rates. We need to understand how trust and confidence might be affected for what is a quite reasonable investment.

4. The trend for a switch from public to private organizations for water supply may affect consumer trust in the new supplier (due to concern that the primary motive is profit), although not necessarily confidence that a quality potable water is delivered.

\section{Acknowledgements}

We would like to thank Ir Toine Ramaker, Ir, Irene Vloerbergh and Dr Walter Wehrmeyer who assisted with the literature reviews associated with the material presented in the present paper.

\section{References}

Ajzen, I. (1985). From intentions to actions: A theory of planned behaviour. In Kuhl, J., and Beckmann, J., (eds.) Action control: from cognition to behaviour. Springer, Berlin, 11-39.

Bellaby, P. (2006) Concepts and methods in the study of trust. TSEC Trust Symposium, Oxford, June 2006.

Bord, R. J. \& O'Connor, R. E. (1992). Determinants of risk perceptions of a hazardous waster site. Risk Analysis, 12(3), 411-416.

Consumer Council for Water (2006b). Using Water Wisely: A Deliberative Consultation.

http://www.ccwater.org.uk/upload/pdf/Using_Water_Wisely_Final_Written_Report.pdf .$\underline{\mathrm{pdf}}$

Earle, T.C. \& Siegrist, M. (2006). Morality information, performance information, and the distinction between trust and confidence. Journal of Applied Social Psychology, 36, 383-416.

Eiser, J.R., Miles, S. \& Frewer, L.J. (2002). Trust, perceived risk and attitudes towards food technologies. Journal of Applied Social Psychology, 32, 2423-2433. 
Fife-Schaw, C.R., Kelay, T., Vloerbergh, I., Ramaker, T., Chenoweth, J. Morrison, G. \& Lundéhn, C. (2007). Consumer Trust and Confidence: An Overview. TECHNEAU Report, http://www.techneau.org .

Finucane, M.L., Alhhakami, A.S., Slovic, P. \&Johnson, S.M. (2000). The affect heuristic in the judgement of risks and benefits. Journal of Behavioural Decision Making, 13, 1-17.

Freudenburg, W. R. (1993), 'Risk and Recreancy: Weber, the Division of Labor, and the Rationality of Risk Perceptions', Social Forces 71(4): 909-32.

Haddad, B. (2004) WateReuse Foundation summary of research needs assessment workshop: Human reactions to water reuse. Appendix I in Southern California Water Recycling Projects Initiative (2004). Successful Public Information and Education Strategies: Technical Memorandum. http://www.usbr.gov/lc/socal/reports/TM_PublicInfoStrategies.pdf

Marks, J. (2003). The sociology of 'disgust' towards the use of reclaimed water. Paper presented at the second national conference of Water Recycling Australia, Brisbane, Australia, September.

http://www.uwi.com.au/rd/publisher/fileUpload/191/attach/Marks\%202003\%20WRA.p $\underline{\mathrm{df}}$

Marks, J.S. (2006). Taking the public seriously: the case of potable and non potable reuse. Desalination, 187, 137-147.

Owen, D. (2002), Masons Water Yearbook 2002-2003, London: Masons Solicitors.

Po, M., Nancarrow, B., Leviston, Z., Porter, N., Syme, G., \& Kaercher, J. (2005). Predicting Community Behaviour in Relation to Wastewater Reuse: What Drives Decisions to Accept or Reject? Melbourne: CSIRO.

Poortinga, W. \& Pidgeon, N. F. (2004) Trust, the asymmetry principle, and the role of prior beliefs. Risk Analysis, 24(6), 1475-1486.

Poortinga, W. \& Pidgeon, N.F. (2005). Trust in Risk Regulation: Cause or Consequence of the Acceptability of GM Food? Risk Analysis, 25, 199-209.

Poortinga, W. \& Pidgeon, N.F. (2006). Prior Attitudes, Salient Value Similarity, and Dimensionality: Toward an Integrative Model of Trust in Risk Regulation. Journal of Applied Social Psychology, 36, 1674-1700.

Roseth, N. (2000) Community Views on Recycled Water, Proceedings Enviro 2000 Towards Sustainability, 9-13 April, Sydney.

Siegrist, M. (1999) A causal model explaining the perception and acceptance of gene technology. Journal of Applied Social Psychology, 29, 2093-2106.

Siegrist, M., Earle, T.C. \& Gutcher, H. (2003). Test of a trust and confidence model in the applied context of electromagnetic field (EMF) risks. Risk Analysis, 23, 705-716. 


\section{Giardia and Bergen}

A case in point is the Giardia (Giardia lamblia) outbreak of October to December 2004 where at least 1300 individuals were infected and probably 5000-6000. The Bergen Giardia outbreak was located to the city centre and attributed to a combination of leaking sewage pipes and insufficient water treatment. Hospital files demonstrate that the epidemic probably started some six weeks before the outbreak was officially recognized (Steen and Damsgaard 2007) and illustrate the difficulty for the water industry in dealing with consumers in such a situation. Nygård et al (2006) reason that the large public health impact of the outbreak was due to late detection and passive surveillance of confirmed cases. The detection of pathogens through monitoring programs has proved ineffective in preventing Giardia or Cryptosporidium outbreaks. Vieira (2007) conclude that monitoring is a reactive approach to building consumer confidence and that a more appropriate approach is whole water cycle risk assessment and management through implementation of water plans.

An independent evaluation presented in May 2006 (SINTEF 2006) confirmed that the municipality had responsibility through not following set procedures for water surveillance and treatment, but did respond well once the outbreak was confirmed. The municipality response included mapping the source of the outbreak, recommendation to boil water for drinking, web and postal information, as well as implementing an interim UV disinfection facility by early 2005 and planning new treatment facilities for 2007 .

Public behaviour and response to the Giardia outbeak is characterized by quiet discontent. The Norwegian national newspapers have reported on the Bergen Giardia outbreak because cases have continued through to 2006 due to a switch to person-toperson infection. The quiet discontent is revealed in newspaper articles quoting anonymous consumer reactions "no-one wants to employ a Giardia sick person ..." and "....because of this no-one wants to be known as a Giardia case". A comparison can be made to the stigma surrounding HIV/AIDS patients.

The public backlash of the Giardia Bergen outbreak is becoming evident in 2007, nearly three years later. The first reaction is a legal case now being brought by a lawyer representing infected individuals against Bergen municipality. The second reaction is the political response to the fine of 800000 Norwegian Crowns imposed on the municipality - there is concern that the fine is trivial compared to the significant health effects that many consumers have suffered.

Nygård, K., Schimmer, B., Sobstad, O., Walde, A., Tveit, I., Langeland, N., Hausken, T and aavitsland, P., 2006, A large community outbreak of waterborne giardiasis delayed detection in a non-endemic urban area, BMC Public Health, 6, 141.

Sintef (2006) Giardia outbreak in Bergen, autumn 2004 - report from the external evaluation committee (in Norwegian).

Steen, K. and Damsgaard, E., 2007, The Giardia epidemic in 2004 and out-of-hours service in Bergen Norway, Tidskrift för den Norske Laegerforening, 127, 187-189. 
Vieira, J.M.P., 2007, Water safety plans: Methodologies for risk assessment and risk management in drinking water systems, IAHS-AISH Publication, 310, 57-67. 


\section{Trust and confidence in water in Accra study}

Recent studies in Accra have studied consumer issues during a time when the system is changing to Private Sector Participation (PSP). Consumers consider that the public water company has not demonstrated the expected duty-of-care in organizing and delivering water, but expect PSP to raise standards and enhance confidence (Sarpong and Lundehn 2006). There is a difference between the response of consumers receiving piped water and those receiving shared or tanker water (Lundehn and Morrison 2007, Sarpong and Lundehn 2006), the former being satisfied and the latter being dissatisfied.

Lundéhn, C; Morrison, G.M. (2007). An assessment framework for urban water systems - a new approach combining environmental systems with service supply and consumer perspectives. In: Morrison, G.M.; Rauch, S. (Eds) Highway and Urban Environment Proceedings of the 8th Highway and Urban Environment Symposium. Alliance for Global Sustainability Bookseries, Vol. 12. (p.559-577) Springer, Amsterdam.

ISBN: 978-1-4020-6009-0

Sarpong Owusu E.; Lundéhn C. (2006). Consumer attitude and trust in Accra water supply (Ghana). Civil and Environmental Engineering, Water Environment Technology, Chalmers, Report no 2006:9, ISSN 162-9162, Göteborg, Sweden. 


\section{Final paragraph}

A number of issues can be identified that cause, or are likely to cause emotional consumer responses.

1. Waterborne disease outbreak, such as occurred in the Bergen Giardia case, particularly where negligence or failure to act on the part of the water company becomes evident. Even with duty-of-care one might expect an emotional response for the presence of pathogens that survive conventional treatment trains.

2. Effects of climate change on water resources and water treatment, as evidenced by rising levels of Natural Organic Matter in drinking water. As consumer awareness of issues of climate change are raised, a response might be anticipated if water supply is affected or interrupted without appropriate preparations being made.

3 . High leakage rates and low replacement rate of the pipe system is becoming a challenge for many European cities with well invested systems. Considerable improvements will be required for the pipe infrastructure, which may lead to increased water rates. We need to understand how trust and confidence might be affected for what is a quite reasonable investment.

4. The trend for a switch from public to private organizations for water supply may affect consumer trust in the new supplier (due to concern that the primary motive is profit), although not necessarily confidence that a quality potable water is delivered. 